\title{
29 años después de la historia
}

29 years after history

\author{
Domingo De la Fuente McIntyre \\ Departamento De Filosofía, San Isidro, Chile (domingodlf@gmail.com)
}

Recibido el 17 de diciembre de 2018; revisado el 10 de febrero de 2019; aceptado el 05 de marzo de 2019; publicado el 22 de marzo de 2019

RESUMEN: El propósito de este artículo es preguntarse por la factibilidad de considerar la democracia liberal como la cúspide de las ideologías humanas. ¿Tenía razón Fukuyama al plantear el fin de la historia - esto es, de la ideología- con el ocaso de la Guerra Fría y la consolidación definitiva de la idea de occidente plasmada en un modelo democrático liberal?

PALABRAS CLAVE: Fukuyama, fin, historia, democracia, liberalismo.

\begin{abstract}
The purpose of this article is to question the feasibility of considering liberal democracy as the pinnacle of human ideology. Was Fukuyama right when he proposed the end of history understood as the advancement of ideology- with the end of the Cold War and the definitive consolidation of the idea of occident, manifested in the model of liberal democracy?
\end{abstract}

KEYWORDS: Fukuyama, end, history, democracy, liberalism.

En el verano de 1989, algunos meses antes de la caída del muro de Berlín, ¿Francis Fukuyama parecía adelantarse en el tiempo al plantear en un breve ensayo llamado The end of history? la tesis que la historia entendida como lucha de ideologías- había llegado a su término, donde el sistema democrático liberal finalizaba por imponerse tras la Guerra Fría. Debido al revuelo que causó este ensayo, tres años más tarde Fukuyama pensador norteamericano de origen japonés- publica como continuación y expansión El fin de la historia y el último hombre recogiendo algunas críticas y comentarios al texto, logrando convertirse en un best seller.

Para la adecuada comprensión de su propuesta, es necesario previamente contextualizar su análisis y los conceptos de los que hace uso el autor para exponer su tesis sobre el fin de la historia. El mismo Fukuyama se encargó de enmarcar conceptualmente su tesis (Fukuyama, 2016, pág. 58), declarando que no es el primero en 
postular el fin de la historia, sino que podemos encontrar en Marx un planteamiento similar, en la medida que éste asumía una direccionalidad en el proceso histórico que llegaría a su culminación con la realización de la utopía comunista. Al anunciar el fin de la historia Fukuyama aclara "Esto no quiere decir que no vayan a producirse más acontecimientos que puedan llenar las páginas de los resúmenes anuales (...), pues la victoria del liberalismo se ha producido principalmente en la esfera de las ideas o de la conciencia” (Fukuyama, 2016, pág. 57)

Francis Fukuyama, en su ensayo El fin de la historia?, afirma que la democracia liberal es la cúspide del desarrollo ideológico humano, y que la humanidad no podrá avanzar más allá de ésta en política o economía. Entrega varias razones para sostener esta tesis, pero la principal es que dicho sistema político resuelve los dos mayores anhelos intrínsecos de la naturaleza humana: la comodidad material y, el más importante, el deseo de reconocimiento. Mi propósito con este ensayo, más que refutar la visión de la naturaleza humana que propone Fukuyama, es argumentar en contra de la democracia liberal como sistema último para el funcionamiento de las sociedades humanas. Para esto, me voy a apoyar en tres líneas argumentativas, y luego esbozaré el marco para una posible solución, definiendo algunas ideas base que debiera seguir un sistema político para realmente ser la mejor solución posible. Mis líneas argumentativas serán tres, a saber: a) el cortoplacismo en el que cae inevitablemente el liberalismo económico, b) la naturaleza autodestructiva de la democracia liberal y, c) la sociedad "nostálgica" que describe Fukuyama en el último capítulo de su ensayo.

a) En una economía que valora la eficiencia económica y la acumulación de capital como la mejor manera de adquirir poder para un individuo de a pie, y una forma directa de aumentar la propia calidad de vida, es inevitable caer en el cortoplacismo. Económicamente, esto se ve reflejado, por ejemplo, en la casi desaparición o reducción a mercados muy pequeños, de productos menos eficientes, en beneficio de productos que produzcan mayor ganancia al productor y a la vez cumplan su función de manera inmediata para el consumidor. Un ejemplo cotidiano es la comida rápida. Con un gran margen de ganancia para el productor (no es casualidad el inmenso poderío económico de cadenas multinacionales como McDonalds), y siendo una solución fácil y efectiva para la necesidad básica que busca solucionar el consumidor, pareciera que no hay ninguna razón para no elegirla y consumirla. Y es esto lo que lleva a tanta gente a elegirla. Es tan buena que otras opciones mucho más sanas y objetivamente superiores a largo plazo, simplemente no pueden competir. Esto lleva a un mercado que aparenta opción, pero que en realidad solo es variado para un sector de la población. Tomás Moulian tiene un pasaje muy interesante e ilustrativo que toca este fenómeno en su libro El consumo me consume, en el fragmento El Mall, la catedral del consumo. Para Moulian, el mall es "un espacio privado con aspecto de espacio público" (1998, pág. 54). Afirma esto ya que, a pesar de ser de libre acceso, lo que encierran sus incitadoras vitrinas solo está destinado a una élite, que puede pagarlo y que es aceptada por el mall como su público objetivo. Los paralelos con el poder político en una democracia liberal son evidentes Otro ejemplo, mucho más grave de esto, se da con los combustibles fósiles, que han depredado durante años al mercado de las 
fuentes de energía renovables, que no van a tomar fuerza a menos de que puedan competir de igual a igual en el mercado, o un gobierno intervenga fuertemente en el mercado a favor de éstas.

Por desgracia, el fenómeno del cortoplacismo no se reduce solo al mercado. La cultura del consumo ya forma parte del humano del siglo XXI, que busca la gratificación inmediata en absolutamente todo. Un ejemplo es, incluso, la fecha de publicación del ensayo de Fukuyama. La primera versión del ensayo ¿El fin de la historia? en discusión fue publicado en 1989, el mismo año de la caída del muro de Berlín, es decir, el mismo año del fin de la Guerra Fría. Fukuyama plantea el fin de la historia el mismo año que se finalizó el mayor conflicto ideológico de la historia, con claros ejemplos de la supervivencia del bando perdedor (Cuba y China) y con la guerra en el mundo de las ideas todavía viva para la gran mayoría de los intelectuales de la época. Esto solo ilustra un problema muy actual, más aún casi 30 años después de la publicación del ensayo. El hombre actual, bombardeado de información por todas partes (especialmente con la masificación de internet), no se toma el tiempo de contemplación necesario para tomar una decisión que vaya más allá de su beneficio inmediato y respuesta rápida. Esto discrepa de manera directa con filósofos como Aristóteles, que proponía que la vida contemplativa y el cultivo de las virtudes era la manera de llegar a la felicidad. Tomando como cierta la definición aristotélica, que un sistema económico y político perpetúe e incentive un modo de vida opuesto al que le traería felicidad a sus miembros no habla bien de la viabilidad a largo plazo de dicho sistema. Más aún, si la definición propuesta por Aristóteles es correcta, aceptar la democracia liberal como culminación de la historia (entendida al modo de Fukuyama, es decir, lucha ideológica) sería absurdo. Con un sistema cuyo fin es la maximización de recursos mediante la producción eficiente y sistematizada, ¿será posible dar un paseo por los jardines del liceo?

b) Pero la democracia liberal tiene un problema mayor, una contradicción inherente a la combinación de dos sistemas, uno político y otro económico, que no son compatibles si se busca mantener el balance de poder entre ambos. Digo que son incompatibles porque una economía liberal degenera, si no hay intervención económica marcada del gobierno - cosa que invalidaría la razón del por qué se instauró la economía liberal en un principio- en un estado en el que, en teoría, cada ciudadano debería tener el mismo poder de decisión y la misma representación dentro del aparataje político del país, pero en la práctica el poder político se ve ostentado siempre por aquel que tenga el poder económico. No tiene sentido instaurar un estado liberal en lo económico y con un sistema político democrático, si la única manera de que el liberalismo no deprede a la democracia con su economía de mercado y apoyo a privados, es justamente controlando el mercado y restringiendo el ámbito de acción de las inversiones privadas. No es suficiente un neoliberalismo a la americana, donde el intervencionismo existe, pero no es suficiente para eliminar las contradicciones internas entre democracia y liberalismo. Tanto el ciudadano pobre como el multimillonario tienen votos que valen lo mismo, y ambos tienen la posibilidad teórica de postular a un cargo público, pero siendo la campaña propagandística una parte fundamental del proceso de elección solo aquellos privados con los medios o conexiones necesarias para financiar su candidatura tendrán una opción real de ganar. En una democracia 
liberal verdadera existe la ilusión de igualdad de poder político por cada ciudadano, cuando la realidad es que la influencia en el estado de cada ciudadano va a ir directamente relacionada con el poder monetario de cada uno. Pero este fenómeno no se ve solo reflejado internamente dentro de la burocracia del país (en los cargos representativos), sino que también la economía inevitablemente subyuga a la política cuando las cifras se vuelven demasiado exorbitantes. Véase el caso de la NRA (National Rifle Association) en EEUU y la situación del lobby en el mismo país. Llega el punto en la acumulación de capital desenfrenado por parte de ciudadanos naturales y asociaciones no gubernamentales en que el libre mercado fagocita todo tipo de representación verdadera de un ciudadano común. Un ejemplo local de momentos en que el desarrollo de la acción económica de privados perjudicó a la democracia es el caso de la guerra civil de 1891en Chile. Como escribe Ricardo Krebs en su Nueva Historia de Chile, luego de una guerra civil en la que el presidente José Manuel Balmaceda es destituido de su cargo y "El poder pasó a manos de una oligarquía formada por mineros, banqueros y salitreros. Ellos, a través de sus disposiciones, frenaron el incipiente desarrollo industrial que se había iniciado" (Krebs, 2002, pág. 340). En otras palabras, vemos como un grupo minoritario y dueño del poder económico, al ver amenazado su control sobre el litio del país por las políticas de estatización de Balmaceda, decide pasar por encima del interés explícito de la población, removiendo de su cargo a un presidente electo democráticamente, truncando el desarrollo económico del país en el proceso.

c) Como último argumento me voy a alejar de la política y la economía, para analizar el efecto de la democracia liberal una vez "terminada la historia”. Fukuyama menciona en el último capítulo de ¿El fin de la historia? el tipo de sociedad que produce una democracia liberal a largo plazo. La describe como una sociedad nostálgica, sin arte ni filosofía, una sociedad triste donde ya nadie pelea por objetivos mayores a sí mismos, viéndose toda ideología reemplazada por el cálculo económico. Pero, si este es el punto final de la democracia liberal ¿cumple esta realmente con su objetivo? En una sociedad sin ideología, sin arte, sin filosofía, se están negando partes fundamentales de la naturaleza del ser humano, reemplazándolas con cálculos de utilidades, informes de presupuesto y demás instrumentos económicos.

Un verdadero sistema ideal debiera negar la naturaleza de la persona, sino que se adaptaría a ella, permitiéndole al humano desenvolverse en la totalidad de sus intereses e inclinaciones para llegar a la autorrealización y la felicidad. Una democracia liberal no resuelve el problema humano, solo propicia un cierto nivel de bienestar material, dando la ilusión de reconocimiento a sus miembros, cuando en realidad solo es capaz de reconocer a la minoría con el poder económico, creándose una sociedad polarizada y distópica, como anticipaban ya autores como Ray Bradbury o Franz Kafka, medio siglo antes del ensayo de Fukuyama. A pesar de que en la introducción de este ensayo afirmé que mi propósito no era rebatir la visión antropológica que plantea Fukuyama, creo que la sociedad "post-histórica" que daría como resultado el triunfo de la democracia liberal es prueba de que sólo el reconocimiento y la comodidad material no son suficientes (dejando de lado si la democracia liberal logra resolverlos o no). Necesitamos algo más, y quizás sea la misma búsqueda de la solución la que nos mantiene alejados de la nostalgia. 
Habiendo expuesto las razones más importantes para estar en contra de la tesis de Fukuyama queda solo proponer una posible solución. Para dar un marco a un posible gobierno que resuelva mejor, o en su totalidad, el problema humano, voy a referirme al concepto de modernidad líquida acuñado por el sociólogo polaco Zygmunt Bauman. Para Bauman, el humano desde la segunda mitad del siglo XX pasó de ser un sujeto con valores fijos y que buscaba soluciones ciertas y duraderas (sólido), a uno que, dada su marcada flexibilidad, le aterra la idea del estancamiento en cuanto a si mismo, sus creencias y su forma de ser, y que no solo no cree en las soluciones permanentes, sino que simplemente no le gustan (líquido) (Bauman, 2011, págs. 6-7). Teniendo en cuenta la naturaleza de sus miembros, un gobierno ideal sería aquel que sea capaz de evolucionar y mantener el dinamismo, así como lo hace el humano post-moderno, presentando a sus miembros la capacidad de mantener y cambiar su individualidad a gusto, y la posibilidad de cambiar sus creencias y luchar por estas tanto como le parezca necesario para mantener su sensación de identidad personal, valor fundamental según Bauman. La naturaleza líquida y cambiante del humano no permite una solución cierta e imperecedera, o por lo menos no la naturaleza actual. Tomando en cuenta esto, podemos afirmar que la historia no ha acabado. Quizás, incluso, no acabe hasta que acabe el humano.

\section{Referencias bibliográficas}

FUKUYAMA, F. (2016). ¿El fin de la historia? y otros ensayos. (J. G.-M. Escobedo, Ed.) Madrid, España: Alianza Editorial.

MOULIAN, T. (1998). El consumo me consume. Santiago, Chile: Lom Ediciones.

BAUMAN, Z. (2011). Liquid modernity. Cambridge. Polity Press.

KREBS, R. (2002) Nueva Historia de Chile. Santiago. Zig-Zag. 